\title{
Features of trinucleotide repeat instability in vivo
}

\author{
Irina V Kovtun ${ }^{1}$, Cynthia T McMurray ${ }^{1}$ \\ ${ }^{l}$ Department of Molecular Pharmacology and Experimental Therapeutics, Mayo Clinic, Rochester, 200 First Street, SW, Rochester, \\ MN 55905, USA
}

Unstable repeats are associated with various types of cancer and have been implicated in more than 40 neurodegenerative disorders. Trinucleotide repeats are located in non-coding and coding regions of the genome. Studies of bacteria, yeast, mice and man have helped to unravel some features of the mechanism of trinucleotide expansion. Looped DNA structures comprising trinucleotide repeats are processed during replication and/or repair to generate deletions or expansions. Most in vivo data are consistent with a model in which expansion and deletion occur by different mechanisms. In mammals, microsatellite instability is complex and appears to be influenced by genetic, epigenetic and developmental factors.

Keywords: microsatellite instability, trinucleotide repeats, base excision repair, break repair, OGG1, Huntington's disease, myotonic dystrophy

Cell Research (2008) 18:198-213. doi: 10.1038/cr.2008.5; published online 1 Jaunary 2008

\section{Introduction}

Microsatellites are generally defined as simple sequences of 1-6 nucleotides that are repeated multiple times and are present in both coding and non-coding regions of the genome. Repetitive sequences are well represented in the eukaryotic genome [1-7] and have been reported to be hot spots for recombination as well as sites for random integration [8-10]. Thus, alterations in simple repetitive sequences lie at the center of DNA evolution and sequence diversity that drives adaptation. On the other hand, changes in repetitive sequences can result in deleterious effects on gene expression and function, leading to disease. Simple trinucleotide repeats (TNR) have taken on special significance in this regard since genomic amplification of TNR is the underlying genetic defect in a number of human diseases including neurodegenerative and neuromuscular diseases and mental retardation [11]. Potential mechanisms for TNR expansion have been extensively reviewed in the last two years [11, 12]. Therefore, in this review, we focus on interpreting the likelihood of the proposed mechanisms in consideration of general features of genome dynamics from different species. The features of microsatellite instability observed in bacteria, yeast, mice, and man can define the

Correspondence: Irina V Kovtun

Tel: +507-284-8911; Fax: +507-284-9111

E-mail: kovtun.irina@mayo.edu magnitude and direction of changes expected at TNRs and provide general clues as to how genomes evolve and how certain instability could contribute to human disease.

\section{Incidence and significance of microsatellites}

Repetitive sequences constitute $30 \%$ of the human genome, and are often sites of deletions and insertions [1-7]. The incidence of repetitive elements is much higher than that of random sequences of the same base composition [3, 4], and the different microsatellites are represented in the genome at different frequencies. For instance, repeats of diand tetranucleotides are more abundant than trinucleotide repeats (TNR) in all eukaryotes [2-6]. However, when the distribution of simple repeats is compared among exons, introns and intragenic regions, TNRs and hexanucleotides prevail in exons in all taxonomic groups [7]. Moreover, TNRs, which are polymorphic in nature, are longer in humans than in other species [3-6]. An evolutionary trend towards expansion of CAG repeats increases in order from monkeys, to apes, to humans [3-6]. For example, the number of CAG repeats in the androgen receptor gene in monkeys is similar to that in rodents, ranging from 1-4 repeats, whereas this number increases to 17 units in great apes and up to 26 in humans [7].

\section{Repetitive sequences and human pathologies}

Remarkably, a high rate of microsatellite instability 
was discovered in human cancers, first noted in cases of hereditary non-polyposis colorectal cancer (HNPCC) [1315]. The most common underlying cause of microsatellite instability in HNPCC is germ line mutation in one or more components of the mismatch repair (MMR) system [13-16]. It is now accepted that unstable maintenance of microsatellite repeats occurs in about $15 \%$ of sporadic colorectal cancers [13-26]. Microsatellite instability is also frequently associated with ovarian cancers $[17,21,22]$ and other malignancies, including tumors of endometrium [22, 23], skin [24], brain [25], stomach [23, 26, 27] and small intestine [26] among others. In most cases of HNPCC [13, $16,18,20]$ and ovarian tumors [17, 21, 22], the majority of known mutations occur in Mlh1 and Msh2. Mutations in Msh6 [19, 22] and Pms2 [25] are observed less frequently, and mutations in Msh3 are rare. In some tumors, Mlh1 deficiency arises from promoter methylation and consequent shut-down of Mlh1 gene expression [28-30]. The hallmark feature of these MMR-defective cancers is a genome-wide increase in spontaneous mutation rate [31-34]. Microsatellite instability in these cancers reflects the inability of MMR to correct post-replicative errors throughout the genome. As a result, polymerase slippage at the repeating unit can give rise to small insertions and deletions $[35,36]$. In both yeast and bacteria, frameshift errors at repetitive sequences increase by 10-100 fold in MMR-defective cells relative to controls $[36,37]$. Analysis of the magnitude and direction of instability at microsatellite loci in HNPCC has revealed that short sequences can undergo small insertions, but the majority of changes are deletions. For example, a set of 10 microsatellites was evaluated in $26 \mathrm{HNPCC}$ patients [38]. In these patients, instability occurred at TNR repeats within the normal Huntington's Disease (HD) and spinocerebellar ataxia (SCA1) loci, among others. However, $65 \%$ of the changes at the HD locus and $74 \%$ of the changes at the SCA1 locus were deletions [38]. The magnitude of the changes in HD was, on the average, loss of 1-3 CAG repeats [38], with the most frequent change being a loss of 1 CAG repeat. Thus, in HNPCC, TNR repeats behave as typical microsatellites when post-replicative repair is defective, and do not undergo expansion as observed in human neurodegenerative diseases such as HD.

\section{Trinucleotide instability and neurodegenerative diseases}

TNR expansion also depends on the MMR system but in ways we do not yet fully understand [39-42]. At least four lines of evidence suggest that mechanisms of expansion in TNR diseases are different from those of HNPCC. First, HNPCC is characterized by a mutator phenotype with genome-wide increase in mutations, yet the TNR expansion is limited to a single disease locus [37] (Figure 1). The limitation to the single disease locus suggests that mutations in MMR repair proteins are unlikely to be the underlying cause for TNR expansion. Second, the insertions and deletions associated with microsatellite instability in HNPCC are small, and the size of the change does not vary extensively regardless of whether they occur within short or long repeats $[33,37]$. In contrast, in the absence of an MMR defect, the length of the TNR tract determines the probability of a deletion or an expansion event [43-46]. TNR repeats associated with neurodegenerative diseases must be above a TNR length threshold (for most TNR diseases it lies in the range of 32-42 repeats, ref. 11) before there is any probability of expanding in number [11, 43-46]. Short TNRs (below threshold) are stable. For intermediate TNR alleles, approaching the threshold, both small deletions and expansions occur at similar rate upon transmission (roughly the same size and frequency as is observed in HNPCC)

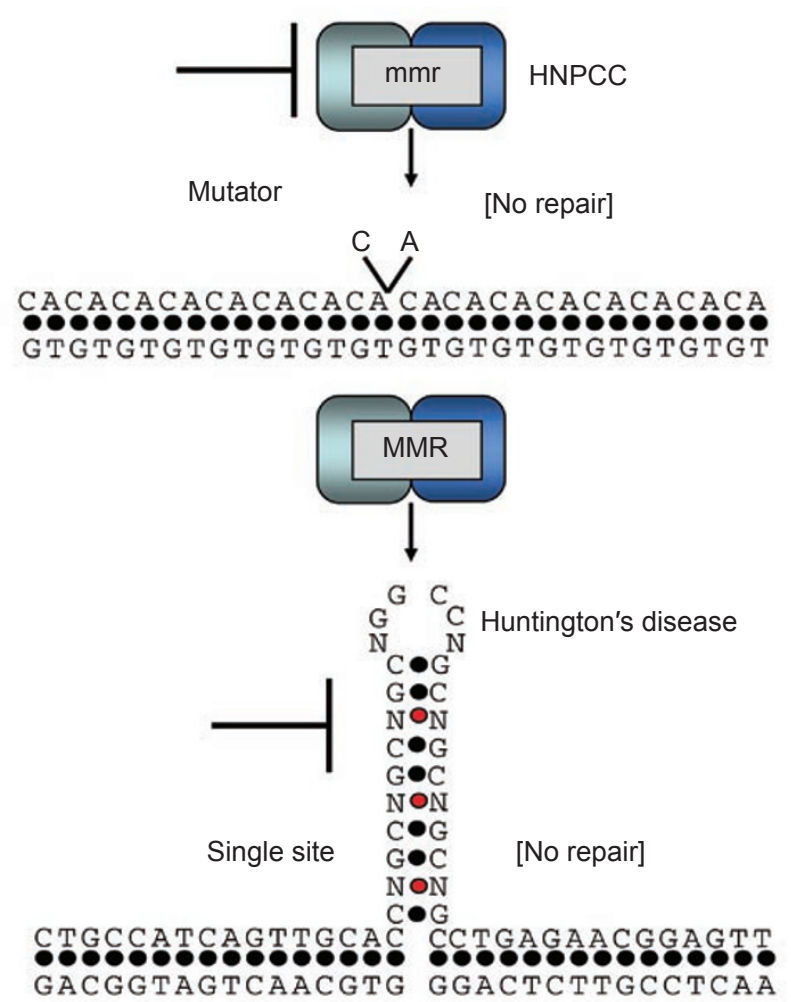

Figure 1 Models of repeat instability for HNPCC and Huntington's disease. During replication, strand slippage can occur. In HNPCC patients the mismatch repair enzymes are defective $(\mathrm{mmr})$ and unable to carry out repair (perpendicular line). Defective mismatch repair increases instability at repeats due to slippage and formation of extrahelical loops. The inability to repair results in genome-wide instability (top). In HD patients, repair enzymes are intact but unable to efficiently recognize and/or repair alternative DNA structures (shown is a DNA hairpin). The repair block occurs at the level of the DNA (bottom), and TNR expansion is primarily limited to the disease allele (single site mutation). 
$[47,48]$. However, once a TNR tract exceeds a threshold, the TNR tract becomes highly prone to expansion, which occurs in approximately $80-90 \%$ of the cases [44-50]. In contrast to the instability in HNPCC, expansion of TNRs within neurodegenerative disease loci occurs in the context of overall genome stability, and the magnitude of TNR expansion in parent-to-child transmission increases with the length of the repeat tract [43-46].

Third, tissue-specific instability occurs during human [51-55] or animal $[54,56]$ development in TNR disorders. Somatic variation in repeat tract length is observed in the brains of individuals affected by Fragile-X [55], HD [52], myotonic dystrophy (DM) [57, 58] and spinobulbar muscular atrophy (SBMA) [59]. Somatic changes at TNR are also found in different tissues among mouse models for these diseases [40-42, 56]. Fourth, in HNPCC, microsatellite instability occurs at a wide range of di-, tri-, and tetra-nucleotide repeats $[33,37]$, yet TNR expansion is somewhat specific for structure-forming sequences [60, 61]. In contrast to HNPCC, DNA repair proteins in TNR patients are normal. Current models suggest that secondary structures such as hairpins, cruciforms and triplexes form at specific sites within the disease loci [60-63]. Stable secondary structures serve as looped precursors for expansion, which occurs after processing and incorporation of the extrahelical DNA into the genome [11, 64-66]. The mechanisms by which loops form within the TNR tracts in DNA, and how they are processed into the eventual expansion, are not fully understood; and several models have been proposed.

\section{General mechanisms for TNR expansion}

Models for expansion have been recently reviewed [12, 66]. In general, the models can be divided into two basic classes, one of which is replication-dependent (Figure 2, ref. 66), and the other one is repair-dependent [66]. It has been a matter of debate as to whether all of these mechanisms can act as independent pathways for expansion, or whether there is a single mechanism. This has been a difficult question to answer since support for various TNR expansion models has arisen from different systems and different cell types, whose properties of replication rates, transcription, and chromatin organization are unlikely to be the same. Studies in bacteria, yeast, mammalian cells, and mouse models have all contributed to the current understanding of TNR expansion as it is found in human diseases.

\section{Comparative analysis of models for triplet expansion}

\section{Bacteria and yeast}

It is generally accepted that changes in the length of

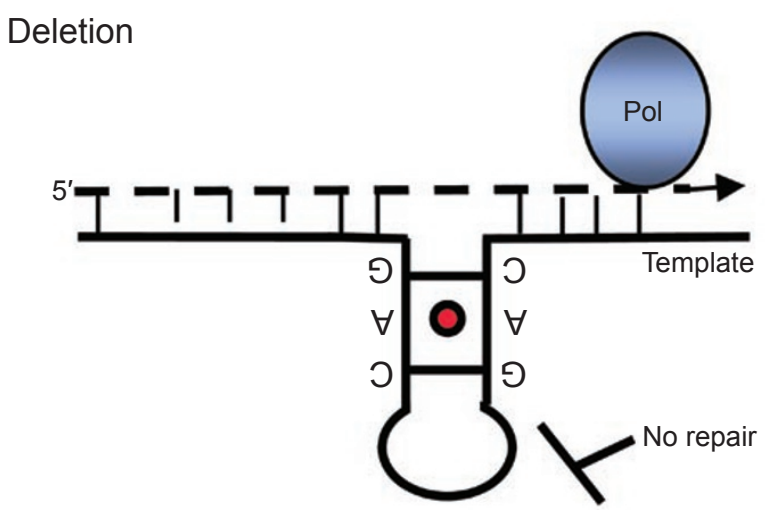

Expansion

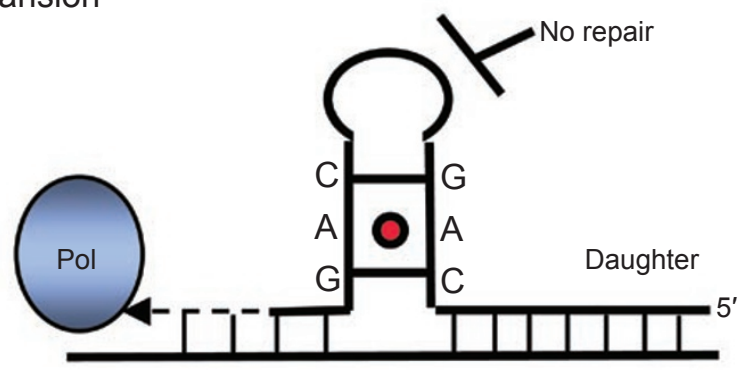

Figure 2 TNR instability caused by polymerase slippage. DNA polymerase strand slippage has been proposed as the primary mechanism for instability of TNR. During replication, the TNR units can misalign resulting in an extrahelical DNA loop that increases TNR length if it occurs on the daughter strand (expansion), and decreases TNR length if it occurs on the template strand (deletion). Loop / hairpin structures when not properly repaired (no repair) (ref. 43) are incorporated into the nascent strand (expansion, bottom) or skipped (deletion, top). Pol is DNA polymerase.

microsatellites occur, on the evolutionary time scale, by a process of polymerase slippage. In this model, microsatellites misalign during replication, resulting in extrahelical DNA loops. Subsequent integration and/or improper resolution of the tract result in gain or loss of repeat units within the duplex DNA. An increase in microsatellite length occurs if slippage is on the daughter strand, and a decrease in microsatellite length occurs if slippage is on the template strand [67-70] (Figure 2). Thus, the earliest model proposed for TNR expansion was the "replication slippage" mechanism.

Indeed, instability at TNRs could be modeled in both bacteria and yeast harboring plasmids with TNR repeats [67-72]. These models are valuable for testing how microsatellites might change during mitosis. Results from multiple laboratories indicate that TNR instability in these systems depends on the sequence, the initial length of the repeat tract, and, strikingly, on its orientation relative to 
the replication origin [67-70]. The mutation rate for TNR sequences capable of forming secondary structures is consistently high, while TNR sequences that do not form secondary structures display mutation rates equivalent to background [69]. The high rate of instability at TNRs suggested that secondary structures might facilitate slippage at TNRs $[12,62,65,66]$. In contrast to the expansion in human neurodegenerative diseases, however, deletion of TNR repeats in bacteria and in yeast occurs roughly 10 times more frequently than insertion events [70-72], a profile more similar to HNPCC than to TNR expansion diseases. If interpreted in a replication slippage model, the strong deletion bias would suggest that looped intermediates form more frequently in the template relative to the daughter strand. The basis for the deletion bias is not presently understood, although proofreading activity of DNA polymerase is likely to be involved [73].

Another poorly understood feature of TNR instability observed in model organisms is orientation dependence. CAG/CTG repeats, for example, are unstable when CTG is the lagging-strand template, but the same sequence is relatively stable with CAG as the lagging-strand template [67-70]. A similar phenomenon has also been observed for CGG/CCG repeats [74-76] and GAA/TCC repeats [77, 78]. Thus, the frequency of TNR instability and the extent of deletion vary depending on the direction of the replication fork progression, despite the fact that the same sequence is being replicated. A simple polymerase slippage model does not predict these outcomes.

The absence of single strand binding protein (SSB) increases the rate of instability in bacteria, consistent with the involvement of the lagging strand [79]. CTG hairpins are somewhat more stable than CAG hairpins in that orientation $[80,81]$. Thus, one model for the orientation-dependence of instability is that transient existence of single stranded DNA during lagging strand synthesis might allow a window of opportunity for hairpins to form. The differential thermodynamic stability of CTG and CAG hairpins, in this model, accounts for the differential rate of hairpin "trapping", or imparts differential repair of CTG relative to CAG hairpins [82]. However, several pieces of evidence are inconsistent with such a model. First, in order for CTG hairpins to differentially form on the lagging strand, the rate of CTG hairpin formation would need to be sufficiently faster than that of $\mathrm{CAG}$ and would need to be insensitive to the presence of SSB. On single strand DNA, however, both CTG and CAG repeats form hairpins spontaneously, and re-anneal under pseudo-first order kinetics at equal rates [81].

Second, a recent in vitro study revealed that both the efficiency and the fidelity of hairpin processing depended critically on the structure of the DNA substrates [nick location and the slip-out composition - CAG versus CTG]
[82]. If hairpins are captured on the template strand during lagging strand synthesis, then the CAG and CTG hairpins would reside opposite of a 3 ' nick. Yet, both CAG and CTG hairpins are repaired poorly under these conditions [82], inconsistent with the extensive deletion bias observed when CTG is the lagging strand template in vivo.

Third, the thermodynamics of CTG hairpin formation would apply only when it resides on the lagging strand template and not when it is on the daughter strand. However, end fraying and hairpin formation at the free end of the Okazaki fragment have been proposed as another model for expansion [83]. A final issue is the fact that TNR instability can also occur on the leading strand during rolling circle replication [84]. Thus, there is no clear model for how hairpins might form in an orientation-dependent manner. Most models agree, however, that replication plays a causative role in generating small insertions and deletions as mutations in pol $\delta$, pol $\alpha, \operatorname{Rad} 27$ and PCNA were all shown to increase TNR instability in yeast [70,85]. Overall, the inability of simple dividing organisms to reproduce the larger expansions observed in human diseases suggested that, if expansion occurred during replication, it must be influenced by additional parameters.

Those parameters are poorly understood. Expansion similar to that observed in human diseases does not appear to arise as a result of transcription in simple organisms. Experimental induction of transcription in replicating plasmids (as well as in mammalian cells) can increase the degree of instability, but the resulting changes are primarily deletions [86-88]. Further, the increase of instability in some reports occurred only when the bacteria passed through stationary phases of cell growth [87]. Emerging evidence suggests that DNA replication blocks, and their resolution through DNA repair pathways, play roles [66].

During primer extension reactions in vitro, pausing is observed at TNRs and other microsatellites [89, 90]. TNRs appear to underlie the impediment, since the pausing is independent of the polymerase. Length- and sequencedependent repeat instability is observed using a number of polymerases including Klenow fragment of Escherichia coli DNA polymerase I, bacteriophage T7 DNA polymerase or the human DNA polymerase $\beta$ [89-93]. In vivo, dramatic stalling at TNRs is observed in yeast during replication fork progression [94-96]. As visualized by two-dimensional gel analysis of replication intermediates, CAG/CTG, CGG/ $\mathrm{CCG}$, and GAA/TTC repeats cause arrest of the replication fork in a length-dependent manner [94-96]. These results suggested that TNR expansion might occur through mechanisms needed to re-start replication [12]. Consistent with that idea, loss of unfolding proteins $[97,98]$ or of helicases such as Werner [99, 100], Bloom [101] and Srs2 [102], all of which facilitate fork progression through difficult DNA 
sequences, increases the level of instability. In E. coli, TNR deletions can also occur after the collapse of the replication fork in an attempt to re-start replication [103]. For example, mutations in recA and recB, recombination proteins needed to resolve replication fork collapse, had a stabilizing effect on $(\mathrm{CAG}) \bullet(\mathrm{CTG})$ repeats [104]. Analysis in yeast indicates that long TNRs are "fragile sites", prone to breakage during replication [105]. Consistent with this idea, a number of studies conducted in bacteria and yeast also provide evidence that gene conversion and recombination, as well as excision repair, frequently result in small deletions and insertions of TNR repeats [104-111].

Although repeat-length changes in bacteria and yeast systems are primarily small, larger TNR expansions are not absent. However, they occur at low frequency and selection systems are required to observe them. One selection method, using 5-fluoroorotic acid, has been particularly informative [112]. Upon selection in yeast, the frequency of large expansions from an existing length of 25 for CAG/CTG [69], CGG/CCG [95], or GAA/TTC [113] repeats is length- and sequence- dependent as observed in human diseases. Moreover, the sizes of the expansion are more consistent with those of human diseases, with gains of around 10-60 repeats, and 20 being the most frequent [113]. Thus, data generated using these selection systems have been informative in identifying key factors affecting large TNR expansions.

For CGG repeats, a mutation in the replication factor $\mathrm{C}$ complex increased the expansion rate by $\sim 50$-fold, suggesting an important role for DNA replication polymerases in the expansion mechanisms [95]. Consistent with this, larger expansions were also observed in the absence of FEN-1/RAD27 in yeast [113]. FEN1/RAD27 is responsible for removal of the flap formed in Okazaki fragments during replication and during repair-dependent synthesis $[114,115]$. Several laboratories have demonstrated that FEN-1 is unable to efficiently process stable secondary structures $[113,114]$, presumably because the $5^{\prime}$ end is not available for FEN-1 loading. Loss of FEN-1/RAD27 in yeast increased the rate of expansion in two distinct steps by [1] increasing the likelihood of flap formation, and [2] inhibiting flap processing, thereby, increasing flap half-life [113]. Contraction rates for CTG and CAG tracts were measured using a simple variation of the selection assay [112]. The rate of contractions by this assay in the $\operatorname{rad} 27 \Delta$ strain was nearly identical for CTG and CAG, at $4.2 \pm 1.2 \times 10^{-3}$ and $5.0 \pm 0.4 \times 10^{-3}$ per cell generation, respectively [113]. Recently, the fate of CAG/CTG repeats was tested in yeast harboring a RAD27 mutant deficient in its endonuclease activity [115]. The TNRs were unstable in these cells. The inability to cleave flaps resulted in a flap equilibration in which various intermediates were formed by annealing to the adjacent primer. Thus, cleavage by $\operatorname{Rad} 27$ is needed to prevent expansion [115]. While TNR expansion is clearly connected to problems arising from replication, all of the examined proteins are also involved in repair of DNA strand breaks. Therefore, whether infrequent expansions detected in various experimental settings arise by DNA replication per se or from repair-dependent synthesis remains an unresolved issue.

Overall, replication and repair problems in model organisms enhance the frequency of TNR instability in the form of small deletions and insertions. Simple models have brought to light the importance of replication stalling and replication fork collapse in TNR instability. However, in general, bacteria and yeast model systems have not yielded the expected insight into the TNR expansion process as might apply to human diseases.

\section{Mammalian systems}

Translation of results from simple model organisms into mammalian systems has been challenging in part due to the variable nature of the mammalian models used. The length of the TNR tract, the replication rate, and the tissue type are among the variables.

Expansion in cultured mammalian cells Mammalian cell models share the property of cell division with yeast and bacteria but at slower rates. While the fate of TNRs in bacteria and yeast overall displays similar trends, different results have been shown for the fate of TNRs in cultured cells obtained from affected individuals. In a number of studies, the endogenous disease-length alleles within HD (CAG repeats) [116], SBMA [CAG repeats] [117] and Fragile X (CGG repeats) [118] loci display little if any instability in cultured cells obtained from patients.

In cultured embryonic fibroblasts from R6/1 mice, CAG repeats in the human HD transgene remained stable in the absence of DNA repair enzymes such as Msh2 and Ogg1 [119]. New genetic assays have been developed using shuttle vectors containing the promoter-TNR-reporter gene sequences [120]. The vector harbors the SV40 origin and the large $\mathrm{T}$ antigen gene allowing portability between primate cell lines [120]. When propagated in cultured cells, CAG of 25-33 repeats contract at frequencies as high as $1 \%$ in both 293T human cells and in COS-1 monkey cells [120]. Plasmids may replicate faster than the cells themselves, so these data indicate that the rate of replication can play a role in the resulting instability. Interestingly, plasmids harboring TNRs delete their repeats during replication in mammalian cells, similar to that in bacteria and yeast. Deletions are also observed during early and rapid cell division in single cells from the 8-cell embryo of R6/1 animals [116], yet no alteration occurred in these animals later in development 
after cells became terminally differentiated.

Taken together these data suggest that the rate of replication is a factor in TNR stability in mammalian cells. The fate of the repeats also depends on the length of the initial repeat tract, which has a large impact on the direction of change $[121,122]$. For example, in primary fibroblasts derived from a fetus with DM1, CTG tracts of 216 repeats expanded to 338-386 repeats with mutation frequencies approaching 100\% [121]. Expansion depended on replication. Both inhibiting replication initiation with mimosine and inhibiting leading- and lagging-strand synthesis with aphidicolin significantly enhanced CTG expansions at the disease allele but not at the short, normal allele [121]. Similarly, CAG repeats in fibroblasts isolated from R6/2 animals harboring multiple copies of a human HD transgene showed significant expansions. After approximately 600 cell doublings, the major CAG peak increased in length from the initial 155 to approximately 170 triplets [123]. In all these cases [121-123], the magnitude of expansion depended on the initial length of the repetitive tract.

Although there are some differences, the fate of repeats in proliferating mammalian cells displays some of the same trends as observed in dividing bacteria and yeast. Overall, data suggest that repeat length and replication rate predict the degree and direction (deletion vs. expansion) of instability. In reality these effects in mammalian cells are more complicated, as they appear to also depend on the cell type. For example, embryonic fibroblasts and lung cells from DM transgenic mice stably maintained their CTG repeats in culture, while repeats from kidney cells were unstable [124]. Thus, locus-specific differences, differences in replication rates and/or tissue-specific factors may be important components affecting the expansion process in mammalian cells [124].

Expansion in vivo All studies in mammalian cell models and in simple organisms are consistent with the notion that replication is a critical component of the expansion mechanism. Whether expansion in a human disease arises from mitotic replication per se or from repair-dependent replication or both is unresolved. For example, long repeats have tendencies to break during cell division, as was shown in yeast [105], therefore, the two processes, replication and repair, are difficult to separate. In addition,

Table1 Effect of DNA repair enzymes on expansion in vivo

\begin{tabular}{|c|c|c|c|c|c|}
\hline $\begin{array}{l}\text { Mouse } \\
\text { model }\end{array}$ & $\begin{array}{l}\text { Deleted } \\
\text { enzyme }\end{array}$ & Genotype & $\begin{array}{l}\text { Effect of deletion } \\
\text { on expansion }\end{array}$ & $\begin{array}{l}\text { Instability } \\
\text { mode }\end{array}$ & Reference \\
\hline \multirow[t]{5}{*}{ HD } & Fen-1 & R6/1/Fen1(-/+) & Some changes* & (i) & 127 \\
\hline & & $R 6 / 1 / M \operatorname{sh} 2(-/-)$ & Expansion abrogation & $(i, s)$ & 39,129 \\
\hline & Msh3 & $R 6 / 1 / M \operatorname{sh} 3(-/-)$ & Expansion abrogation & (s) & 43 \\
\hline & Ogg1 & R6/1/Oggl(-/-) & Significant reduction & (s) & 119 \\
\hline & Nth1 & R6/1/Nth1(-/-) & None & & 119 \\
\hline \multirow[t]{6}{*}{$\mathrm{DM}$} & Pms2 & $D M / P m s 2(-/-)$ & Significant reduction in expansion & (s) & 174 \\
\hline & Msh2 & $D M / M \operatorname{sh} 2(-/-)$ & Expansion abrogation & $(i, s)$ & 42 \\
\hline & Msh3 & $D M / M \operatorname{sh} 3(-/-)$ & Expansion abrogation & $(i, s)$ & 40 \\
\hline & Msh6 & $D M / M \operatorname{sh} 6(-/-)$ & Decrease in mean change & (s) & 42 \\
\hline & & & Increase in frequency & (s) & 40 \\
\hline & Fen-1 & DM/Fen-1(-/+) & None & $(\mathrm{s})$ & 128 \\
\hline
\end{tabular}

HD and DM transgenic animals were used to test the importance of DNA repair enzymes in TNR expansion in mammals in vivo. The genotypes are indicated. Fen-1 (Flap Endonuclease); Msh2, MutS homologue 2; Msh3, MutS homologue 3; Msh6, MutS homologue 6; AAG, alkyladenine glycosylase; Ogg1, 7,8-dihydro-8-oxo-guanine-DNA glycosylase; NTH1, homologue of Escherichia coli endonuclease III. * A decrease in deletions and an increase in expansions were only observed in male offspring. ** A decrease in the magnitude of expansion was observed. Mode of instability: (i) -intergenerational, (s)-somatic expansion. Decrease in mean change is a decrease in the magnitude of age-dependent expansion compared to animals that are wild type for the corresponding repair enzyme. 
functional alterations in replication and repair proteins in mammals have not been easy to evaluate. In mice, deletion of key replication and/or repair proteins relevant to TNR expansion is often embryonic lethal. For example, mice knockout for polymerase $\beta$ [125] and for FEN-1 [126] are not viable. Furthermore, in vivo tools to examine the relative importance of replication on expansion in animals are also limited due to the fact that cell proliferation in most adult tissues has ceased. Despite all these issues, mouse models have proven to be extremely valuable in validating proposed mechanisms for expansion.

The effect of FEN-1 haploinsufficiency on TNR expansion has been examined in heterozygous animals (Table 1). While there was no visible effect on age-dependent expansion at the HD locus in somatic tissues of HD/Fen-l(+/-) mice as compared to wild type littermates, a decrease in deletions and an increase in expansions were observed in male offspring [127] (Table 1). Similarly, no alterations in CTG tract size were observed in somatic cells from DM/Fen-1(+/-) animals [128]. Repeat profiles between wild type, Fen1(+/-) and Fenl(-/-) early embryos have also been compared in the latter study. No difference was found, leading to a conclusion that FEN-1 is not essential for maintaining the stability of TNR in early embryonic divisions [128]. FEN-1 is an essential replication protein, but it is also needed for gap filling synthesis during repair of DNA strand breaks and recombination. The lack of effects on expansion in Fen 1 (-/-) embryos is not easy to interpret. The results may indicate that there is embryonic selection for stable alleles. Another possibility is that during rapid cell divisions TNRs tend to undergo deletions, counteracting the expansion events that may occur.

Germ cells as a model to assess expansion mechanisms Germ cells from transgenic animals have been a valuable model to further assess the importance of replication in causing expansion in mammals. The pool of germ cells in the adult male includes spermatogonia (SG), which divide, spermatocytes (SC), which undergo meiotic recombination, and spermatids (ST), which differentiate (and allow repair without replication) to generate mature sperms (Figure $3 \mathrm{~A})$. The degree of expansion at each stage of the germ cell development has been informative.

In a mouse model for $\mathrm{HD}$, expansion of $\mathrm{CAG}$ is primarily detected in haploid ST [129]. Detection at this post-meiotic stage of development would indicate that expansion does not require replication. However, different results were obtained in germ cells of HD patients. In laser capture micro-dissected cells, expansion of the CAG tract was observed in premeiotic cells (which presumably included SG and SC) as well as in ST [130]. The reason for the discrepancy between findings in the mouse model and in human samples is not yet clear. However, differences in germ cell development and in lifespan may contribute [131]. In human spermatogonial stem cells, the lifetime number of cell divisions is estimated to be approximately an order of magnitude higher than in the mouse. There may be fewer opportunities for mouse premeiotic cells to accumulate expansion mutations [130]. If true, this would predict that expansions in the sperm of affected individu-
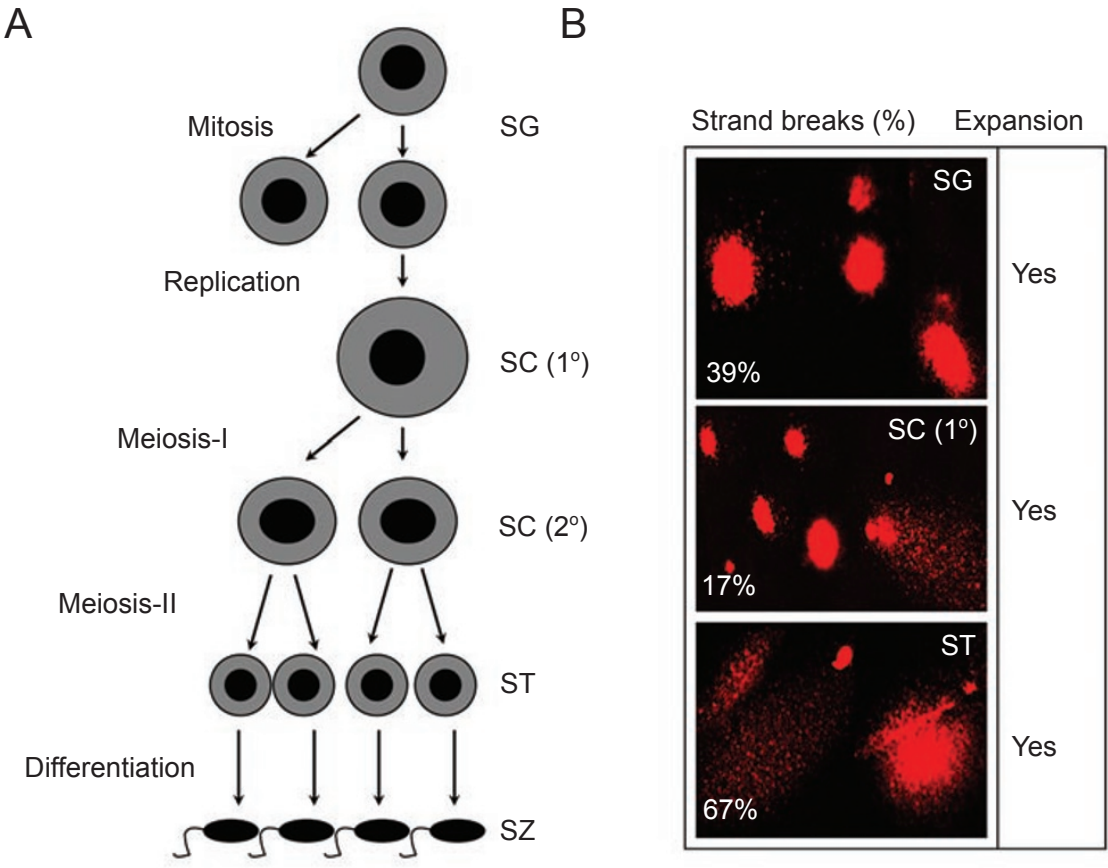

Figure 3 Expansion and strand breaks in developing germ cells in HD. (A) A schematic diagram of spermatogenesis. Each developmental stage is shown; SG, spermatogonia; SC, spermatocytes; ST, spermatids; SZ, spermatozoons. SG undergo mitotic division and produce primary SC $\left(1^{\circ}\right)$ which after first meiotic division produce secondary SC $\left(2^{\circ}\right)$. In the second meiotic round ST are generated. They undergo terminal differentiation producing SZ. (B) Comet assay for single strand breaks in sorted germ cells of HD transgenic mice. The \% of cells with breaks is shown. Expansion is detected only in ST in HD transgenic mice [129] but is observed in SG, SC and ST in HD patients [130]. 
als would increase with age. However, in a recent study of HD patients, no correlation was found between the CAG repeat-length variation in sperm and the age of the HD subjects at the time of sperm donation [131]. Neither parental age nor birth order was shown to have a significant effect on inherited repeat-length changes in this group of HD patients. Expansions observed in post-mitotic germ cells must occur by repair-dependent mechanisms. The mechanisms at play in dividing cells may be polymerase slippage or replication stalling and re-start. Slippage, even in mammalian cells, appears to most frequently generate deletions. Thus, break-dependent repair synthesis, as has been observed in yeast, is an alternative process that could generate expansions $[12,94,95,105]$. Developing mouse germ cells are known to accumulate strand beaks, which can be observed by the comet assay (Figure 3B). Presently, differences between mouse and human germ cell models in HD remain unresolved.

In contrast to HD, CTG repeats in DM mice expand in both dividing SG and terminally differentiated ST [132]. The repeat tract continues to increase in length with age, indicating that expansions are continuously produced during cell proliferations throughout life. In humans, expansions at the DM locus have been observed in dividing cells of early embryo [133]. Why HD alleles undergo deletion and DM alleles undergo expansion in dividing cells is not known. However, a key difference between TNRs at the HD and DM loci is the length of the tract. The CTG repeat at the

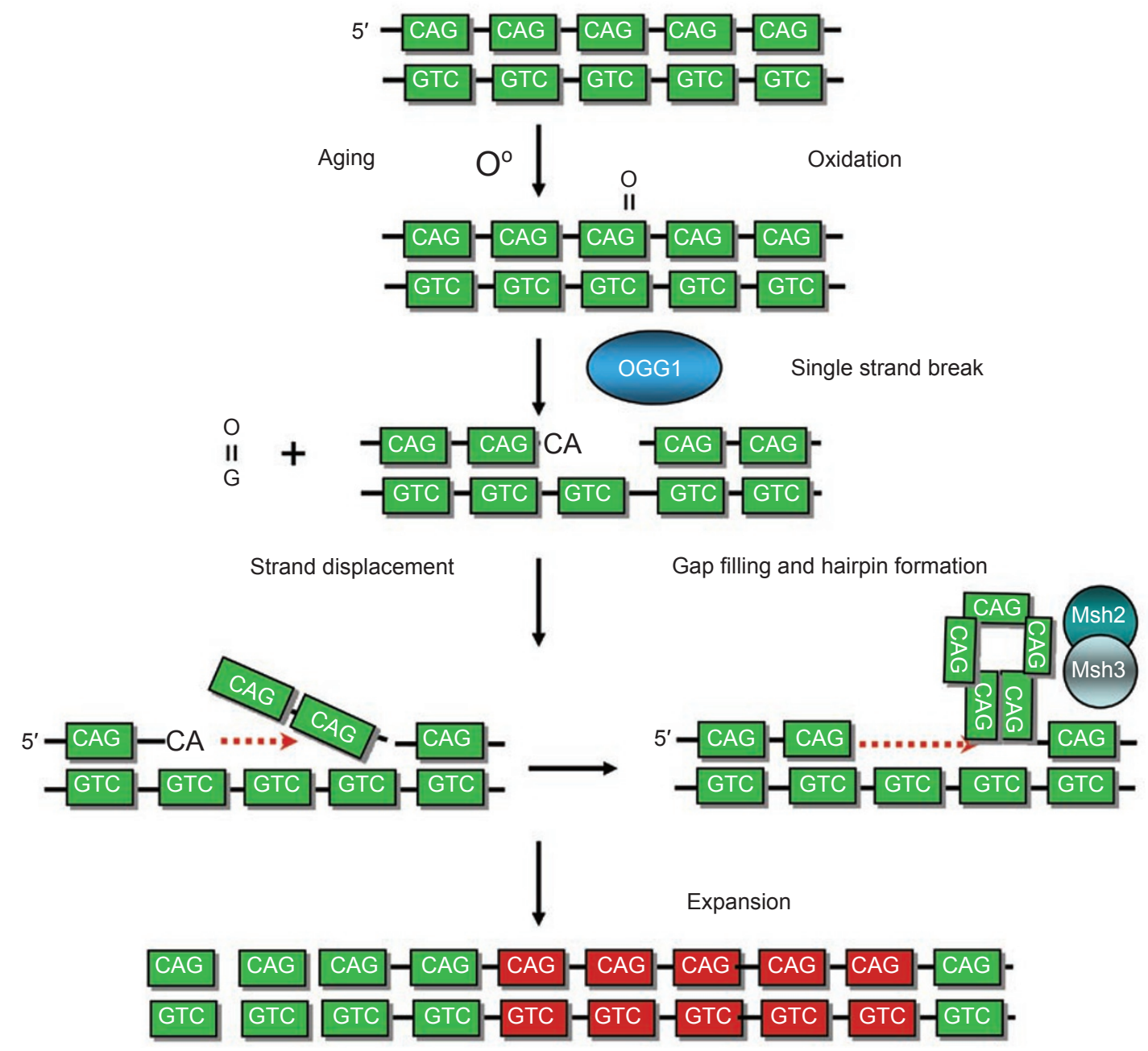

Figure 4 Base excision repair model for age-dependent somatic TNR expansion in HD. During aging, endogenous oxidative damage arising from mitochondrial respiration creates oxidative DNA lesions. Oxidative lesions, such as 8-oxo-G, tend to accumulate within CAG tract with age $(\mathrm{G}=0)$. Under conditions of normal BER, OGG1/APE cleavage produces a single strand break, which facilitates hairpin formation and allows strand displacement during gap-filling synthesis. The lifetime of the hairpin is sufficiently prolonged by MSH2/MSH3 binding to allow ligation of the hairpin loop. Green bars are CAG or CTG, as indicated; red bars are the repeats added in the expansion event. 
DM locus resides in a non-transcribed region of the gene and can grow to thousands of units $[57,58]$. As discussed above, in simple organisms, long repeats cause replication stalling, often resulting in strand breaks $[12,94,95$, 105]. Thus, break-dependent replication may account for the presence of CTG expansions in dividing cells. In the HD gene, on the other hand, the CAG tract is within the protein-coding region and rarely exceeds 130 units [4548]. Presumably, this is due to selective pressure. The HD protein is essential for viability in mammals. If HD alleles were too long, the resulting defective gene product would diminish cell survival. At the HD locus, the shorter CAG tract may not pose severe blocks for the polymerase and may tend to break less often. The existence of locus-specific factors that influence HD and DM cannot be excluded, and they are being explored actively.

In vivo mouse models and somatic expansion Mouse models have also shed light on the mechanism of somatic repeat-length changes, which are now believed to modulate the severity and onset of the diseases [53, 54, 134]. Somatic expansion occurs at an inherited, expanded TNR. Alterations in repeat length have been observed in affected areas in HD and DM patients [52, 53, 57] and in the tissues of aging transgenic mouse models for $\operatorname{HD}[41,54,56,129]$ and DM $[40,135,136]$. We and others have shown that the inherited repeat tracts in HD transgenic mice are stably maintained from birth until 4 months but begin to expand in non-dividing brain cells at midlife [56, 129]. Expanded CAG tracts continue to increase in length as these animals age [129], thereby serving as templates for synthesis of increasingly toxic HD proteins in the brain and other somatic tissues. Thus, in addition to the inherited expansion, somatic changes in repeat tracts in the brain may contribute to the disease by modulating its severity and onset.

The factors that cause somatic instability have been the subject of intense research. The importance of strand breakage in causing expansion in simple organisms prompted evaluation of whether TNR expansion was affected by factors involved in DNA repair in mice (Table 1). DM animals were crossed with mouse knockouts for key DNA repair enzymes. Knockouts of Rad52, $\operatorname{Rad54}$, and $\mathrm{Ku}$ had no effect on expansion of the CTG repeat in DM mice [42]. In contrast to simple model organisms, TNR expansion in mammals does not appear to require enzymes generally needed for repair of double strand breaks (DSB) [42]. Recent evidence has revealed that somatic expansion in mammals more likely occurs by a base excision repair mechanism [119] (Figure 4). Age-dependent changes at the human HD transgene locus occur concomitantly with the accumulation of oxidative DNA damage. Importantly, loss of 7,8-dihydro-8-oxo-guanine-DNA glycosylase (Ogg1), a DNA glycosylase responsible for removal of oxidized guanines, suppresses TNR expansion in HD mice (Table 1). Deletion of other DNA glycosylases, however, does not suppress expansion (Table 1). Thus, age-dependent somatic expansion associated with HD occurs in the process of removing oxidized base lesions. TNR expansion in both germ cells and somatic cells of HD [39, 41, 43, 129] and DM [40, 42] transgenic mice requires the MMR proteins Msh2 and Msh3, but not Msh6. Thus it is possible that TNR expansion depends on the cooperation of base excision repair and MMR pathways through interactions of OGG1 and the Msh2/Msh3 heterodimer during the removal of oxidative DNA damage (Figure 4).

Taken together, the data from simple models to man suggest that both replication and repair processes are likely to contribute to TNR expansion. Future studies will refine the mechanistic models.

\section{Genomic and chromatin factors governing microsat- ellite instability}

\section{Common cis-acting factors}

In the simple, rapidly dividing organisms, bacteria and yeast, cis-elements influencing TNR fate have been limited to the sequence of the repeat, its length and the presence of interruptions [67-70, 137].

Data on TNR instability from human studies and various transgenic and knock-in mouse models suggest that sequences immediately surrounding the repeats as well as overall chromatin context might also be important in determining TNR stability. Analysis of flanking elements for a number of different repeats has revealed that the most expandable loci are those located within $\mathrm{CpG}$ islands [138]. Indeed, the methylation status of $\mathrm{CpG}$ can alter the stability of the CGG repeats at the Fragile X loci [138-140]. Treatment of mammalian cells in vitro with methyltransferase inhibitors leads to the loss of the methyl group from 5-Me-cytosine, causing subsequent destabilization of the CTG/CAG repeats at the DM locus [141]. DNA methylation is typically associated with tight chromatin packaging and gene silencing. Analysis of the DM locus reveals that the CTG repeats form a functional component of an insulator element. Methylation of this locus occurs in congenital forms of DM, prevents the binding of CTCF, and disrupts the insulator function [142]. These remarkable findings suggest that chromatin context has an impact on the stability of TNRs.

Analogous to bacteria and yeast, the location of DNA replication origin relative to the repeat stretch can influence the stability and the direction of change (deletion vs. expansion; ref. 143) for human TNR disease loci. While several disease loci have been examined, including spinal cerebel- 
lar ataxia type 7, HD, SBMA, FMR1 and FMR2 [144-146], the effects of the position of a replication origin have not yet been well characterized, The HD and SCA-7 repeats served as the lagging strand template. On the other hand, origin firing at the SBMA locus occurred on either side of the repeat [144]. The replication origin for the FMR2 locus maps to the promoter region of the gene [145]. In addition, the FMR2 replication origin coincided with $\mathrm{CpG}$ islands and tended to fire late in S phase [145]. Precisely how the position of a replication origin determines TNR instability in the mammalian genome in vivo remains unclear. Mammalian origins of replication have yet to be fully mapped. Nevertheless, TNR instability is thought to be influenced by many factors including chromatin organization [142], DNA methylation [138-141], and transcription etc.

\section{Expansion in human diseases and mouse models: similari- ties and differences}

Among model organisms, mice have so far been shown to best recapitulate the expansion in human TNR diseases. Transgenic or knock-in mouse models for TNR diseases have consistently demonstrated a trend towards expansion, both somatically and inter-generationally $[40,41,54,56$, $129,135,136]$. Although they show an expansion bias similar to that in humans, TNRs in the mouse genome appear to have a higher threshold for instability. For example, only when a repeat stretch inserted into the mouse genome was very long, has expansion been observed [40, 41, 54, $56,128,135,136]$. While moderately-expanded TNRs are known to be highly unstable in humans and to expand further in successive generations, they are stably transmitted in mice [147-151]. Furthermore, in contrast to humans, long TNRs inserted in the mouse genome rarely show big leaps in repeat number over a single transmission. These differences suggest that genomic context and/or chromatin organization might play a significant role in determining the stability of microsatellites at a specific locus.

The transgenic and knock-in mouse models suggest that the site of transgene integration as well as the amount of human genomic sequence flanking the repeat affects the level of instability. For example, TNR within a cDNA inserted into the mouse genome often exhibited no instability despite a relatively high number of repeat units $[148,149]$. In contrast, transgenic mice that had large pieces of human genomic DNA (kilobases) as the repeat context showed more instability $[40,41,54,56]$. Additionally, mice that had long repeats inserted into the endogenous gene (knock-in) or into a transgene, tended to show more instability [40, 41, $54,56,152]$. None, of the models however recapitulated a threshold length for instability comparable to that observed in humans suggesting the existence of regulatory factors that differ between mice and humans.

\section{Fragility and cell cycle control}

Very little is known about the influence of chromatin organization and/or chromatin remodeling on microsatellite instability. Initial experiments in yeast have provided evidence that CAG/CTG and CGG/CCG tracts are prone to break in vivo [105, 108, 153, 154]. It has been hypothesized that stretches of these repeats might represent fragile sites $[105,153,154]$, and that they are more susceptible to breakage and DNA damage [155]. Fragile sites have been described in yeast [156-159] and mammalian cells [160]. Common fragile sites in the mammalian genome are generally defined as loci that exhibit gaps and breaks under conditions of replicative stress $[155,160,161]$. Perturbations in DNA replication often result in DSB at the fragile sites $[161,162]$ and eventually may lead to gross chromosomal rearrangements, such as translocations, deletions, and inversions [162, 163]. Rare fragile sites, on the other hand, are thought to arise from expanded di- or trinucleotide repeats [164] which can break in vivo in the absence of replicative stress [105, 108, 153, 154]. It has been suggested that DNA lesions may initiate the strand breakage [153, 154].

The mechanism underlying fragility in general is not well understood. Extensive studies in yeast have revealed properties that fragile sites may share. First, some were demonstrated to include repetitive sequences such as palindromes, inverted repeats, and Ty telomeric elements that are capable of forming structures [156, 165-167]. Second, yeast fragile sites are situated on chromosomes in the areas of slow-moving DNA replication forks and origins of replication which fire late $[161,168,169]$ and often lead to DSB $[161,165]$.

Cell cycle control is one of the cellular pathways designed to prevent chromosomal instability. Checkpoints function during the cell cycle to ensure the correct transmission of genetic material. Checkpoint proteins interact with the DNA replication machinery and respond to various threats to DNA, including damage, replication fork blocks and formation of aberrant DNA structures. Checkpoints can arrest the cell cycle and activate appropriate cellular responses $[159,170,171]$. Consistently, defects in checkpoint or cell cycle progression proteins increase chromosomal instability and re-arrangements [159, 169-173]. The role of checkpoint proteins in TNR instability has been examined in yeast. Lahiri et al. have found that deletion of Mec1 (homologue of human ATR) and Rad53 (homologue of human Chk2) resulted in increased fragility of expanded CAG repeats [173]. Significantly higher rates of deletions have been observed in these mutant strains as compared to wild type cells. The authors hypothesized that repair of DNA damage-stalled replication forks and of breaks and gaps at long CAG repeats in checkpoint-deficient strains 
occurred with less fidelity, and thus, led to deletions.

There are fewer results available on checkpoint regulation and fragile sites in mammalian systems. There is, however, evidence suggesting that mammalian fragile sites possess some of the properties that have been described in yeast - i.e., slower replication fork progression and susceptibility to DSB $[161,165,165,168]$. The differences between the mammalian and yeast fragile sites include the larger sizes (can be greater than $100 \mathrm{~kb}$ ) and the more complex composition for the former, as they do not consist of a single type of repeat $[160,166]$. Whether fragility is sequence-specific or is dictated by chromatin organization remains unclear. Emerging data on the involvement of the DNA repair machinery [39-41, 42, 119, 132] in expansion suggest that chromatin environment may determine the susceptibility of a particular repetitive locus to DNA damage and the consequent instability that follows repair.

\section{Conclusion}

It is clear that many biological transactions determine whether TNR expand or contract. However, data from simple organisms to man have revealed several features that are common among all systems. First, expansion depends on both replication and repair. Second, in the context of mitosis most TNR appear to contract rather than expand. There is a strong deletion bias at TNR tracts in simple organisms and in proliferating mammalian cells. Third, expansion appears to be associated with long TNR tracts at both the DM and HD loci. Fourth, long alleles are subject to breakage. Taken together, the facts implicate repeat length as a critical, and perhaps even a unifying factor in the expansion mechanism, which could tie together disparate findings as to the fate of TNR at different disease loci. Single and double strand breaks arising from replication stress may explain why expansion depends on both replication and repair proteins. Alternatively, replication may be required in the context of gap filling synthesis. Although the complex phenomenon of TNR expansion is not yet fully understood, studies in a number of in vivo systems are uncovering features of expansion mechanisms that can be further tested by the scientific community.

\section{Acknowledgments}

This work was supported by the Mayo Foundation, the National Institutes of Health grants K12 CA 90628 (IVK), NS40738 (CTM) and GM 066359 (CTM) (USA). We thank Drs C Spiro (Department of Health Science Research, Mayo Clinic, Rochester, USA) and W Lang (Department of Molecular Pharmacology and Experimental Therapeutics, Mayo Clinic, Rochester) for careful reading of the manuscript.

\section{References}

1 Tautz D. Hypervariability of simple sequences as a general source for polymorphic DNA markers. Nucleic Acids Res 1989; 17:6463-6471.

2 Mrázek J, Guo X, Shah A. Simple sequence repeats in prokaryotic genomes. Proc Natl Acad Sci USA 2007; 104:8472-8477.

3 Toth G, Gaspari Z, Jurka J. Microsatellites in different eukaryotic genomes: survey and analysis. Genome Res 2000; 10:967-981.

4 Jurka J, Pethiyagoda C. Simple repetitive DNA sequences from primates: compilation and analysis. J Mol Evol 1995; 40:120126.

5 Gáspári Z, Ortutayb C, Tóth G. Divergent microsatellite evolution in the human and chimpanzee lineages. FEBS Lett 2007; 581:2523-2526.

6 Beckman JS, Weber JL. Survey of human and rat microsatellites. Genomics 1992; 12:627-631.

7 Djian P, Hancock JM, Chana HS. Codon repeats in genes associated with human diseases: fewer repeats in the genes of nonhuman primates and nucleotide substitutions concentrated at the sites of reiteration. Proc Natl Acad Sci USA 1996; 93:417-421.

8 Durkin SG, Glover TW. Chromosome Fragile Sites. Annu Rev Genet 2007 Jul 3; doi:10.1146/annurev.genet.41.042007.165900.

9 Yant SR, Wu X, Huang Y, Garrison B, Burgess SM, Kay MA. High-resolution genome-wide mapping of transposon integration in mammals. Mol Cell Biol 2005; 6:2085-2094.

10 Jeffreys AJ, Holloway JK, Kauppi L, et al. Meiotic recombination hot spots and human DNA diversity. Philos Trans R Soc Lond B Biol Sci 2004; 359:141-152.

11 Gatchel JR, Zoghbi HY. Diseases of unstable repeat expansion: mechanisms and common principles. Nat Rev Gene 2005; 6:743755.

12 Mirkin SM. Expandable DNA repeats and human disease. Nature 2007 447:932-940.

13 Kwak EL, Chung DC. Hereditary colorectal cancer syndromes: an overview. Clin Colorectal Cancer 2007; 6:340-344.

14 Lynch HT, de la Chapelle A. Hereditary colorectal cancer. $N$ Engl J Med 2003; 348:919-932.

15 Peinado MA, Malkhosyan S, Velazquez A, Perucho M. Isolation and characterization of allelic loss and gains in colorectal tumors by arbitrarily primed polymerase chain reaction. Proc Natl Acad Sci USA 1992; 89: 10065-10069.

16 Liu B, Parsons R, Papadopoulos N, et al. Analysis of mismatch repair genes in hereditary non-polyposis colorectal cancer patients. Nat Med 1996; 2:169-174.

17 Forgacs E, Wren JD, Kamibayashi C, et al. Searching for microsatellite mutations in coding regions in lung, breast, ovarian and colorectal cancers. Oncogene 2001; 20:1005-1009.

18 Chan TL, Yuen ST, Kong CK, et al. Heritable germline epimutation of MSH2 in a family with hereditary nonpolyposis colorectal cancer. Nat Genet 2006; 38:1178-1183.

19 Miyaki M, Konishi M, Tanaka K, et al. Germline mutation of MSH6 as the cause of hereditary nonpolyposis colorectal cancer. Nat Genet 1997; 17:271-272.

20 Hitchins M, Williams R, Cheong K, et al. MLH1 germline epimutations as a factor in hereditary nonpolyposis colorectal cancer. Gastroenterology 2005; 129:1392-1399.

21 Suchy J, Kurzawski G, Jakubowska A, Lubinski J. Ovarian cancer of endometrioid type as part of the Msh6 gene mutation phenotype. J Hum Genet 2001; 47:529-531. 
22 Wijnen J, de Leeuw W, Vasen H, et al. Familial endometrial cancer in female carriers of MSH6 germline mutations. Nat Genet 1999; 23:142-144.

23 Chiaravalli AM, Furlan D, Facco C, et al. Immunohistochemical pattern of hMsh2/ hMlh1 in familial and sporadic colorectal, gastric, endometrial and ovarian carcinomas with instability in microsatellite sequences. Vichows Archiv 2001; 438:39-48.

24 Castiglia D, Pagani E, Alvino E, et al. Biallelic somatic inactivation of the mismatch repair gene MLH1 in a primary skin melanoma. Genes Chromosomes Cancer 2003; 37:165-175.

25 Krüger S, Kinzel M, Walldorf C, et al. Homozygous PMS2 germline mutations in two families with early-onset haematological malignancy, brain tumours, HNPCC-associated tumours, and signs of neurofibromatosis type 1. Eur J Hum genet 2007 Sep 12; doi:10.1038/sj.ejhg.5201923.

26 Suter CM, Martin DI, Ward RL. Germline epimutation of MLH1 in individuals with multiple cancers. Nat Genet 2004; 36:497501.

27 Bacani J, Zwingerman R, Di Nicola N, et al. Tumor microsatellite instability in early onset gastric cancer. J Mol Diagn 2005; 7:465-477.

28 Herman JG, Umar A, Polyak K, et al. Incidence and functional consequences of hMLH1 promoter hypermethylation in colorectal carcinoma. Proc Natl Acad Sci USA 1998; 95:6870-6875.

29 Strathdee G, MacKean MJ, Illand M, Brown R. A role for methylation of the hMlh1 promoter in loss of hMlh1 expression and drug resistance. Oncogene 1999; 18:2335-2341.

30 Kane MF, Loda M, Gaida GM, et al. Methylation of the hMLH1 promoter correlates with lack of expression of hMLH1 in sporadic colon tumors and mismatch repair-defective human tumor cell lines. Cancer Res 1997; 57:808-811.

31 Kashi Y, King DG. Simple sequence repeats as advantageous mutators in evolution. Trends Genet 2006; 22:253-259.

32 Loeb LA. A mutator phenotype in cancer. Cancer Res 2001; 61:3230-3239.

33 Beckman RA, Loeb LA. Genetic instability in cancer: theory and experiment. Semin Cancer Biol 2005; 15:423-435.

34 Sammalkorpi H, Alhopuro P, Lehtonen R, et al. Background mutation frequency in microsatellite-unstable colorectal cancer. Cancer Res 2007; 67:5691-5698.

35 Sia EA, Kokoska RJ, Dominska M, Greenwell P, Petes TD. Microsatellite instability in yeast: dependence on repeat unit size and DNA mismatch repair genes. Mol Cell Biol 1997; 17:28512858.

36 Viguera E, Canceill D, Ehrlich SD. Replication slippage involves DNA polymerase pausing and dissociation. EMBO J 2001; 20:2587-2795.

37 Harr B, Todorova J, Schlotterer C. Mismatch repair-driven mutational bias in D. melanogaster. Mol Cell 2002; 10:199-205.

38 Goellner GM, Tester D, Thibodeau S, et al. Different mechanisms underlie DNA instability in Huntington disease and colorectal cancer. Am J Hum Genet 1997; 60:879-890.

39 Manley K, Shirley, TL, Flaherty L, Messer A. MSH2 deficiency prevents in vivo somatic instability of the CAG repeat in Huntington disease transgenic mice. Nat Genet 1999; 23:471-473.

40 van den Broek WJ, Nelen M, Wansink DG, et al. Somatic expansion behavior of the (CTG)n repeat in myotonic dystrophy knock-in mice is differentially affected by Msh3 and Msh6 mismatch-repair proteins. Hum Mol Genet 2002; 11:191-199.
41 Wheeler V, Lebel LA, Vrbanac V, Teed A, te Riele H, MacDonald ME. Mismatch repair gene Msh2 modifies the timing of early disease in $\mathrm{Hdh}(\mathrm{Q} 111)$ striatum. Hum Mol Genet 2003; 12:273281.

42 Savouret C, Brisson E, Essers J, et al. CTG repeat instability and size variation timing in DNA repair-deficient mice. EMBO $J$ 2003; 22: 2264-2273.

43 Owen BA, Badger II JD, Yang Z, et al. (CAG)(n)-hairpin DNA binds to Msh2-Msh3 and changes properties of mismatch recognition. Nat Structural Mol Biol 2005; 12:663-670.

44 Cummings CJ, Zoghbi HY. Trinucleotide repeats: mechanisms and pathophysiology. Ann Rev Genom Hum Genet 2000; 1:281328.

45 Duyao M, Ambrose C, Myers R, et al. Trinucleotide repeat length instability and age of onset in Huntington's disease. Nat Genet 1993; 4:387-392.

46 Zuhlke C, Riess O, Bockel, B, Lange H, Thies U. Mitotic stability and meiotic variability of the (CAG)n repeat in the Huntington disease gene. Hum. Mol. Genet. 1993; 2:2063-2067.

47 Norremolle A, Sorensen SA, Fenger K, Hasholt L. Correlation between magnitude of CAG repeat length alterations and length of the paternal repeat in paternally inherited Huntington's disease Clin. Genet 1995; 47: 113-119.

48 Chong SS, Almqvist E, Telenius H, et al. Contribution of DNA sequence and CAG size to mutation frequencies of intermediate alleles for Huntington disease: evidence from single sperm analysis. Hum Mol Genet 1997; 6:301- 309.

49 Goldberg P, McMurray CT, Zeisler J, et al. Increased instability of intermediate alleles in families with sporadic Huntington's disease compared to similar sized intermediate alleles in the general population. Hum Mol Genet 1995; 4:1911-1918.

50 Leeflang EP, Tavare S, Marjoram P, et al. Analysis of germline mutation spectra at the Huntington's disease locus supports a mitotic mutation mechanism. Hum Mol Genet 1999; 8:173-183.

51 Leeflang EP, Zhang L, Tavare S, et al. Single spermanalysis of the trinucleotide repeats in the Huntington's disease gene: quantification on the mutation frequency spectrum. Hum Mol Genet 1995; 4:1519-1526.

52 Telenius H, Kremer B, Goldberg YP, et al. Somatic and gonadal mosaicism of the Huntington disease gene CAG repeat in brain and sperm. Nat Genet 1994; 6:409-414.

53 Kennedy L, Evans E, Chen CM, et al. Dramatic tissue-specific mutation length increases are an early molecular event in Huntington disease pathogenesis. Hum Mol Genet 2003; 12:33593367.

54 Kennedy L, Shelbourne PF. Dramatic mutation instability in HD mouse striatum: does polyglutamine load contribute to cellspecific vulnerability in Huntington's disease? Hum Mol Genet 2000; 9:2539-2544.

55 Wohrle D, Hennig I, Vogel W, Steinbach P. Mitotic stability of fragile $\mathrm{X}$ mutations in differentiated cells indicates early postconceptional trinucleotide repeat expansion. Nat Genet 1993; 4:140-142.

56 Mangiarini L, Sathasivam K, Mahal A, Mott R, Seller M, Bates GP. Instability of highly expanded CAG repeats in mice transgenic for the Huntington's disease mutation. Nat Genet 1997; 15:197-200.

57 Wong LJ, Ashizawa T, Monckton DG, Caskey CT, Richards CS. Somatic heterogeneity of the CTG repeat in myotonic dystrophy 
is age and size dependent. Am J Hum Genet 1995; 56:114-122.

58 Jansen G, Willems P, Coerwinkel M, et al. Gonosomal mosaicism in myotonic dystrophy patients: involvement of mitotic events in (CTG)n repeat variation and selection against extreme expansion in sperm. Am J Hum Genet 1994; 54:575-585.

59 Zhang L, Leeflang EP, Yu J, Arnheim N. Studying human mutations by sperm typing: instability of CAG trinucleotide repeats in the human androgen receptor gene. Nat Genet 1994; 7:531535.

60 Chen X, Mariappan SVS, Catasti P, et al. Hairpins are formed by the single DNA strands of the fragile X triplet repeats: structure and biological implications. Proc Natl Acad Sci USA 1995; 92:5199-5203.

61 Gacy AM, Goellner G, Juranic N, Macura S, McMurray CT. Trinucleotide repeats that expand in human disease form hairpin structures in vitro. Cell 1995; 81:533-540.

62 McMurray CT. DNA secondary structure: a common and causative factor for expansion in human disease. Proc Natl Acad Sci USA 1999; 96: 1823-1825.

63 Mitas M, Yu M, Dill J, Kamp TJ, Chambers EJ, Haworth S. Hairpin properties of single-stranded DNA containing a GC-rich triplet repeat: (CTG) $)_{15}$. Nucleic Acids Res 1995; 23:1050-1059.

64 Gacy AM, McMurray CT. Influence of hairpins on template reannealing at trinucleotide repeat duplexes: a model for slipped DNA. Biochemistry 1998; 37:9426-9434.

65 Sinden RR, Pytlos-Sinden MJ, Potaman VN. Slipped strand DNA structures. Front Biosci 2007; 12:4788-4799.

66 Kovtun IV, McMurray CT. Models of repair underlying trinucleotide DNA expansion. In: Wells R, Ashizawa T, eds. Genetic instabilities and ${ }_{n}$ eurological diseases. Amsterdam: Elsevier/Academic Press 2006; 679-690.

67 Kang S, Jaworski A, Ohshima K, Wells RD. Expansion and deletion of CTG repeats from human disease genes are determined by the direction of replication in E. coli. Nat Genet 1995; 10:213-218.

68 Freudenreich $\mathrm{CH}$, Stavenhagen JB, Zakian VA. Stability of a CTG/CAG trinucleotide repeat in yeast is dependent on its orientation in the genome. Mol Cell Biol 1997; 17:2090-2098.

69 Miret JJ, Pessoabrandao L, Lahue RS. Orientation-dependent and sequence specific expansions of CTG/CAG trinucleotide repeats in Saccharomyces cerevisiae. Proc Natl Acad Sci USA 1998; 95:12438-12443.

70 Schweitzer JK, Livingston DM. The effect of DNA replication mutations on CAG tract stability in yeast. Genetics 1999; 152:953-963.

71 Hashem VI, Rosche WA, Sinden RR. Genetic assays for measuring rates of (CAG).(CTG) repeat instability in Escherichia coli. Mutat Res 2002; 502:25-37.

72 Kroutil LC, Kunkel TA. Deletion errors generated during replication of CAG repeats. Nucleic Acids Res 1999; 27:3481-3486.

73 Zahra R, Blackwood JK, Sales J, Leach DR. Proofreading and secondary structure processing determine the orientation dependence of CAG - CTG trinucleotide repeat instability in Escherichia coli. Genetics 2007; 176:27-41.

74 Shimizu M, Gellibolian R, Oostra BA, Wells RD. Cloning, characterization and properties of plasmids containing CGG triplet repeats from the FMR-1 gene. J Mol Biol 1996; 258:614-626.

75 Balakumaran BS, Freudenreich CH, Zakian VA. CGG/CCG repeats exhibit orientation-dependent instability and orientation- independent fragility in Saccharomyces cerevisiae. Hum Mol Genet 2000; 9:93-100.

76 Hirst MC, White PJ. Cloned human FMR1 trinucleotide repeats exhibit a length- and orientation-dependent instability suggestive of in vivo lagging strand secondary structure. Nucleic Acids Res 1998; 26:2353-2358.

77 Pollard LM, Sharma R, Gomez M, et al. Replication-mediated instability of the GAA triplet repeat mutation in Friedreich ataxia. Nucleic Acids Res 2004; 3:5962-5971.

78 Heidenfelder BL, Makhov AM, Topal MD. Hairpin formation in Friedreich's ataxia triplet repeat expansion. J Biol Chem 2003; 278:2425-2431.

79 Rosche WA, Jaworski A, Kang S, et al. Single-stranded DNAbinding protein enhances the stability of CTG triplet repeats in Escherichia coli. J Bacteriol 1996; 178:5042-5044.

80 Hartenstine MJ, Goodman MF, Petruska J. Base stacking and even/odd behavior of hairpin loops in DNA triplet repeat slippage and expansion with DNA polymerase. J Biol Chem 2000; 275:18382-18390.

81 Gacy AM, McMurray CT. Influence of hairpins on template reannealing at trinucleotide repeat duplexes: a model for slipped DNA. Biochemistry 1998; 37:9426-9434.

82 Panigrahi GB, Lau R, Montgomery SE, Leonard MR, Pearson CE. Slipped (CTG)•(CAG) repeats can be correctly repaired, escape repair or undergo error-prone repair. Nat Struct Mol Biol 2005; 12:654-662.

83 Gordenin DA, Kunkel TA, Resnick MA. Repeat expansion--all in a flap? Nat Genet 1997; 16:116-118.

84 Iyer RR, Wells RD.Expansion and deletion of triplet repeat sequences in Escherichia coli occur on the leading strand of DNA replication. J Biol Chem 1999; 274:3865-3877.

85 Schweitzer JK, Livingston DM. Expansions of CAG repeat tracts are frequent in a yeast mutant defective in Okazaki fragment maturation. Hum Mol Genet 1998; 7:69-74.

86 Schumacher S, Pinet I, Bichara M. Modulation of transcription reveals a new mechanism of triplet repeat instability in Escherichia coli. J Mol Biol 2001; 307:39-49.

87 Bowater RP, Jaworski A, Larson JE, Parniewski P, Wells RD.Transcription increases the deletion frequency of long CTG. CAG triplet repeats from plasmids in Escherichia coli. Nucleic Acids Res 1997; 25:2861-2868.

88 Lin Y, Dion V, Wilson JH. Transcription promotes contraction of CAG repeat tracts in human cells. Nat Struct Mol Biol 2006; 13:179-180.

89 Kang S, Ohshima K, Shimizu M, Amirhaeri S, Wells RD. Pausing of DNA synthesis in vitro at specific loci in CTG and CGG triplet repeats from human hereditary disease genes. J Biol Chem 1995; 270:27014-27021.

90 Ohshima K, Wells RD. Hairpin formation during DNA synthesis primer realignment in vitro in triplet repeat sequences from human hereditary disease genes. J Biol Chem. 1997; 272:1679816806.

91 Hartenstine MJ, Goodman MF, Petruska J. Weak strand displacement activity enables human DNA polymerase beta to expand CAG/CTG triplet repeats at strand breaks. J Biol Chem 2002; 277:41379-41389.

92 Petruska J, Hartenstine MJ, Goodman MF. Analysis of strand slippage in DNA polymerase expansions of CAG/CTG triplet repeats associated with neurodegenerative disease. $\mathrm{J} \mathrm{Biol} \mathrm{Chem}$ 
1998; 273:5204-5210.

93 Heidenfelder BL, Topal MD. Effects of sequence on repeat expansion during DNA replication. Nucleic Acids Res 2003; 31:7159-7164.

94 Samadashwily GM, Raca G, Mirkin SM. Trinucleotide repeats affect DNA replication in vivo. Nature Genet 1997; 17:298-304.

95 Pelletier R, Krasilnikova MM, Samadashwily GM, Lahue R, Mirkin SM. Replication and expansion of trinucleotide repeats in yeast. Mol Cell Biol 2003; 23:1349-1357.

96 Krasilnikova MM, Mirkin SM. Replication stalling at Friedreich's ataxia (GAA)n repeats in vivo. Mol Cell Biol 2004; 24:22862295.

97 Fukuda H, Katahira M, Tsuchiya N, et al. Unfolding of quadruplex structure in the G-rich strand of the minisatellite repeat by the binding protein UP1. Proc Natl Acad Sci USA 2002; 99:12685-12690.

98 Fukuda H, Katahira M, Tanaka E, et al. Unfolding of higher DNA structures formed by the d(CGG) triplet repeat by UP1 protein. Genes Cells 2005; 10:953-962.

99 Fry M, Loeb LA. Human Werner syndrome DNA helicase unwinds tetrahelical structures of the fragile $\mathrm{X}$ syndrome repeat sequence d(CGG)n. J Biol Chem 1999; 274:12797-802.

100 Kamath-Loeb AS, Loeb LA, Johansson E, Burgers PM, Fry M. Interactions between the Werner syndrome helicase and DNA polymerase delta specifically facilitate copying of tetraplex and hairpin structures of the $\mathrm{d}(\mathrm{CGG}) \mathrm{n}$ trinucleotide repeat sequence. $J$ Biol Chem 2001; 276:16439-16446.

101 Wang W, Bambara RA. Human Bloom protein stimulates flap endonuclease 1 activity by resolving DNA secondary structure. J Biol Chem 2005; 280:5391-5399.

102Bhattacharyya S, Lahue RS. Srs2 helicase of Saccharomyces cerevisiae selectively unwinds triplet repeat DNA. J Biol Chem 2005; 280:33311-33317.

$103 \mathrm{Kim}$ SH, Rytlos MJ, Sinden RR. Replication restart: a pathway for (CTG).(CAG) repeat deletion in Escherichia coli. Mutat Res 2006; 595:5-22.

104Hashem VI, Rosche WA, Sinden RR. Genetic recombination destabilizes (CTG)n.(CAG)n repeats in E. coli. Mutat Res 2004; 554:95-109.

105Freudenreich, CH, Kantro, SM, Zakian VA. Expansion and length-dependent fragility of CTG repeats in yeast. Science 1998; 270:853-856.

106Paques F, Leung, WY, Haber JE. Expansions and contractions in a tandem repeat induced by double-strand break repair. $\mathrm{Mol}$ Cell Biol 1998; 18:2045-2054.

107Richard GF, Dujon B, Haber JE. Double-strand break repair can lead to high frequencies of deletions within short $C A G / C T G$ trinucleotide repeats. Mol Gen Genet 1999; 261:871-882.

108Jankowski C, Nasar F, Nag DK. Meiotic instability of CAG repeat tracts occurs by double-strand break repair in yeast. Proc Natl Acad Sci USA 2000; 97:2134-2139.

109Richard GF, Goellner GM, McMurray CT, Haber JE. Recombination-induced CAG trinucleotide repeat expansions in yeast involve the MRE11/RAD50/XRS2 complex. EMBO J 2000; 19:2381-2390.

110 Jakupciak JP, Wells RD. Gene conversion (recombination) mediates expansions of CTG•CAG repeats. J Biol Chem 2000; 275:40003-40013.

111 Parniewski P, Bacolla A, Jaworski A, Wells RD. Nucleotide exci- sion repair affects the stability of long transcribed $\left(\mathrm{CTG}^{*} \mathrm{CAG}\right)$ tracts in an orientation-dependent manner in Escherichia coli. Nucleic Acids Res 1999; 27:616-623.

112 Dixon MJ, Bhattacharyya S, Lahue RS. Genetic assays for triplet repeat instability in yeast. Methods Mol Biol 2004; 277:29-45.

113 Spiro C, Pelletier R, Rolfsmeier ML, et al. Inhibition of FEN-1 processing by DNA secondary structure at trinucleotide repeats. Mol Cell 1999; 4:1079-1085.

114 Liu Y, Kao HI, Bambara RA. Flap endonuclease 1: a central component of DNA metabolism. Annu Rev Biochem 2004; 73:589-615.

115 Liu Y, Zhang H, Veeraraghavan J, Bambara RA, Freudenreich $\mathrm{CH}$. Saccharomyces cerevisiae flap endonuclease 1 uses flap equilibration to maintain triplet repeat stability. Mol Cell Biol 2004; 24:4049-4064.

116 Kovtun IV, Thornhill, AR, McMurray CT. Somatic deletion events occur during early embryonic development and modify the extent of CAG expansion in subsequent generations. Hum Mol Genet 2004; 13:3057-3068.

117 Spiegel R, La Spada, AR, Kress W, Fischbeck KH, Schmid W. Somatic stability of the expanded CAG trinucleotide repeat in X-linked spinal and bulbar muscular atrophy. Hum Mutat 1996; 8:32-37.

118 Wohrle D, Hennig I, Vogel W, Steinbach P. Mitotic stability of fragile $\mathrm{X}$ mutations in differentiated cells indicates early postconceptional trinucleotide repeat expansion. Nat Genet 1993; 4:140-142.

119 Kovtun IV, Liu Y, Bjoras M, Klungland A, Wilson SH, McMurray CT. OGG1 initiates age-dependent CAG trinucleotide expansion in somatic cells. Nature 2007; 447:447-452.

120Farrell BT, Lahue RS. CAG/CTG repeat instability in cultured human astrocytes. Nucleic Acids Res 2006; 34:4495-4505.

121 Yang Z, Lau R, Marcadier JL, Chitayat D, Pearson CE. Replication inhibitors modulate instability of an expanded trinucleotide repeat at the myotonic dystrophy type 1 disease locus in human cells. Am J Hum Genet 2003; 73:1092-1010.

122 Wohrle D, Kennerknecht I, Wolf M, Enders H, Schwemmle S, Steinbach P. Heterogeneity of DM kinase repeat expansion in different fetal tissues and further expansion during cell proliferation in vitro: evidence for a casual involvement of methyl-directed DNA mismatch repair in triplet repeat stability. Hum Mol Genet 1995; 4:1147-1153.

123 Manley K, Pugh J, Messer A. Instability of the CAG repeat in immortalized fibroblast cell cultures from Huntington's disease transgenic mice. Brain Res 1999; 835:74-79.

124Gomes-Pereira M, Fortune MT, Monckton DG. Mouse tissue culture models of unstable triplet repeats: in vitro selection for larger alleles, mutational expansion bias and tissue specificity, but no association with cell division rates. Hum Mol Genet 2001; 10:845-854.

$125 \mathrm{Gu}$ H, Marth JD, Orban PC, Mossmann H, Rajewsky K. Deletion of a DNA polymerase beta gene segment in T cells using cell type-specific gene targeting. Science 1994; 265:103-106.

126Kucherlapati M, Yang K, Kuraguchi M, et al. Haploinsufficiency of Flap endonuclease (Fen1) leads to rapid tumor progression. Proc Natl Acad Sci USA 2002; 99:9924-9929.

127 Spiro C, McMurray CT. Nuclease-deficient FEN-1 blocks Rad51/ BRCA1-mediated repair and causes trinucleotide repeat instability. Mol Cell Biol 2003; 23:6063-6674. 
128 van den Broek WJ, Nelen MR, van der Heijden GW, Wansink DG, Wieringa B. Fen1 does not control somatic hypermutability of the $(\mathrm{CTG})(\mathrm{n}) *(\mathrm{CAG})(\mathrm{n})$ repeat in a knock-in mouse model for DM1. FEBS Lett 2006; 580:5208-5214.

129 Kovtun IV, McMurray CT. Trinucleotide expansion in haploid germ cells by gap repair. Nat Genet 2001; 27:407-411.

130 Yoon SR, Dubeau L, de Young M, Wexler NS, Arnheim N. Huntington disease expansion mutations in humans can occur before meiosis is completed. Proc Natl Acad Sci USA 2003; 100:8834-8838.

131 Wheeler VC, Persichetti F, McNeil SM, et al. Factors associated with HD CAG repeat instability in Huntington disease. $J$ Med Genet 2007; 44:695-701.

132 Savouret C, Garcia-Cordier C, Megret J, te Riele H, Junien C, Gourdon G. MSH2-dependent germinal CTG repeat expansions are produced continuously in spermatogonia from DM1 transgenic mice. Mol Cell Biol 2004; 24:629-637.

133 De Temmerman N, Sermon K, Seneca S, et al. Intergenerational instability of the expanded CTG repeat in the DMPK gene: studies in human gametes and preimplantation embryos. Am J Hum Genet 2004; 75:325-329.

134 Veitch NJ, Ennis M, McAbney JP; US-Venezuela Collaborative Research Project, Shelbourne PF, Monckton DG. Inherited CAG. CTG allele length is a major modifier of somatic mutation length variability in Huntington disease. DNA Repair (Amst) 2007; 6:789-789.

135Seznec H, Lia-Baldini AS, Duros C, et al. Transgenic mice carrying large human genomic sequences with expanded CTG repeat mimic closely the DM CTG repeat intergenerational and somatic instability. Hum Mol Genet 2000; 9:1185-1194.

136Monckton DG, Coolbaugh MI, Ashizawa KT, Siciliano MJ, Caskey CT. Hypermutable myotonic dystrophy CTG repeats in transgenic mice. Nat Genet 1997; 15:193-196.

137Dixon MJ, Lahue RS. DNA elements important for CAG.CTG repeat thresholds in Saccharomyces cerevisiae. Nucleic Acids Res 2004; 32:1289-1297.

138Brock GJ, Anderson NH, Monckton DG. Cis-acting modifiers of expanded $\mathrm{CAG} / \mathrm{CTG}$ triplet repeat expandability: associations with flanking $\mathrm{GC}$ content and proximity to $\mathrm{CpG}$ islands. Hum Mol Genet 1999; 8:1061-1067.

139 Wöhrle D, Salat U, Gläser D, et al. Unusual mutations in high functioning fragile $\mathrm{X}$ males: apparent instability of expanded unmethylated CGG repeats. Med Genet 1998; 35:103-111.

140Nichol K, Pearson CE. CpG Methylation Modifies the Genetic Stability of cloned repeat. Genome Res 2002; 12:1246-1256.

141 Gorbunova V, Seluanov A, Mittelman D, Wilson JH. Genomewide demethylation destabilizes CTG.CAG trinucleotide repeats in mammalian cells. Hum Mol Genet 2004; 13:2979-2989.

142Filippova GN, Thienes CP, Penn BH, et al. CTCF-binding sites flank CTG/CAG repeats and form a methylation-sensitive insulator at the DM1 locus. Nat Genet 2001; 28:335-343.

143Cleary JD, Nichol K, Wang YH, Pearson CE. Evidence of cis-acting factors in replication-mediated trinucleotide repeat instability in primate cells. Nat Genet 2002; 31:37-46.

144Nenguke T, Aladjem MI, Gusella JF, et al. Candidate DNA replication initiation regions at human trinucleotide repeat disease loci. Hum Mol Genet 2003 12:1021-1028.

145Chastain PD 2nd, Cohen SM, Brylawski BP, Cordeiro-Stone M, Kaufman DG. A late origin of DNA replication in the trinucleo- tide repeat region of the human FMR2 gene. Cell Cycle 2006; 5:869-872.

146Gray SJ, Gerhardt J, Doerfler W, Small LE, Fanning E. An origin of DNA replication in the promoter region of the human fragile X mental retardation (FMR1) gene. Mol Cell Biol 2007 27:426437.

147 Gourdon G, Radvanyi F, Lia AS, et al. Moderate intergenerational and somatic instability of a 55-CTG repeat in transgenic mice. Nat Genet 1997; 15:190-192.

148 Bingham PM, Scott MO, Wang S, et al. Stability of an expanded trinucleotide repeat in the androgen receptor gene in transgenic mice. Nat Genet 1995; 9:191-196.

149 Goldberg YP, Kalchman MA, Metzler M, et al. Absence of disease phenotype and intergenerational stability of the $\mathrm{CAG}$ repeat in transgenic mice expressing the human Huntington disease transcript. Hum Mol Genet 1996; 5:177-185.

150Hodgson JG, Agopyan N, Gutekunst CA, et al. A YAC mouse model for Huntington's disease with full-length mutant huntingtin, cytoplasmic toxicity, and selective striatal neurodegeneration. Neuron 1999; 23:181-192.

151 Burright EN, Clark HB, Servadio A, et al. SCA1 transgenic mice: a model for neurodegeneration caused by an expanded CAG trinucleotide repeat. Cell 1995; 82:937-948.

152Gomes-Pereira M, Foiry L, Nicole A, et al. CTG trinucleotide repeat "big jumps": large expansions, small mice. PLoS Genet 2007; 3:e52.

153Balakumaran BS, Freudenreich $\mathrm{CH}$, Zakian VA. CGG/CCG repeats exhibit orientation-dependent instability and orientation-independent fragility in Saccharomyces cerevisiae. Hum Mol Genet 2000; 9:93-100.

154Callahan JL, Andrews KJ, Zakian VA, Freudenreich CH. Mutations in yeast replication proteins that increase CAG/CTG expansions also increase repeat fragility. Mol Cell Biol 2003; 23:7849-7860.

155 Richards RI. Fragile and unstable chromosomes in cancer: Causes and consequences. Trends Genet 2001; 17:339-345.

156Lemoine FJ, Degtyareva NP, Lobachev K, Petes TD. Chromosomal translocations in yeast induced by low levels of DNA polymerase a model for chromosome fragile sites. Cell 2005; 120:587-598.

157Raveendranathan M, Chattopadhyay S, Bolon YT, Haworth J, Clarke DJ, Bielinsky AK. Genome-wide replication profiles of $\mathrm{S}$-phase checkpoint mutants reveal fragile sites in yeast. $E M B O$ J 2006; 25:3627-3639.

158Bielinsky AK. Scarce but scary. Nat Genet 2007; 39:707-708.

159Admire A, Shanks L, Danzl N, et al. Cycles of chromosome instability are associated with a fragile site and are increased by defects in DNA replication and checkpoint controls in yeast. Genes Dev 2006; 20:159-173.

160 Glover TW, Berger C, Coyle J, Echo B. DNA polymerase alpha inhibition by aphidicolin induces gaps and breaks at common fragile sites in human chromosomes. Hum Genet 1984; 67:136142.

161 Casper A, Nghiem P, Arlt MF, Glover TW. ATR regulates fragile site stability. Cell 2002; 111:779-789.

162 Glover TW, Stein CK Chromosome breakage and recombination at fragile sites. Am J Hum Genet 1988; 43:265-273.

163 Wang L, Paradee W, Mullins C, et al. Aphidicolin-induced FRA3B breakpoints cluster in two distinct regions. Genomics 
1997; 41:485-488.

164 Sutherland GR, Baker E, Richards RI. Fragile sites still breaking. Trends Genet 1998 14:501-506.

165Lobachev KS, Gordenin DA, Resnick MA. The Mre11 complex is required for repair of hairpin-capped double-strand breaks and prevention of chromosome rearrangements. Cell 2002; 108:183193

166Zlotorynski E, Rahat A, Skaug J, et al. Molecular basis for expression of common and rare fragile sites. Mol Cell Biol 2003; 23:7143-7151.

167Glover TW, Arlt MF, Casper AM, Durkin SG. Mechanisms of common fragile site instability. Hum Mol Genet 2005; 14:R197R205.

168Bielinsky AK. Replication origins: why do we need so many? Cell Cycle 2005; 2:307-309.

169 Cha RS, Kleckner N. ATR homolog Mec1 promotes fork progression, thus averting breaks in replication slow zones. Science
2006; 297:602-606.

170Rodriguez R, Meuth M. Chk1 and p21 cooperate to prevent apoptosis during DNA replication fork stress. Mol Biol Cell 2006; 17:402-412.

171 Arlt MF, Casper AM, Glover TW. Common fragile sites. Cytogenet Genome Res 2003; 100:92-100.

172 Cobb JA, Schleker T, Rojas V, Bjergbaek, Tercero TA, Gasser SM. Replisome instability, fork collapse, and gross chromosomal rearrangements arise synergistically from $\mathrm{Mec} 1$ kinase and RecQ helicase mutations. Genes Dev 2005; 19:3055-3069.

173 Lahiri M, Gustafson TL, Majors ER, Freudenreich CH. Expanded CAG repeats activate the DNA damage checkpoint pathway. Mol Cell 2004; 15:287-293.

174 Gomes-Pereira M, Fortune MT, Ingram L, McAbney JP, Monckton DG. Pms2 is a genetic enhancer of trinucleotide CAG.CTG repeat somatic mosaicism: implications for the mechanism of triplet repeat expansion. Hum Mol Genet 2004; 13:1815-1825. 